\title{
Emotional expressiveness of the vocalist: a cross-sectional study
}

\author{
Alina Shpyrka* \\ Larysa Bondarenko** \\ Ganna Kondratenko*** \\ Alexandr Shpyrka****
}

*Corresponding author, Borys Grinchenko Kyiv University, 18/2, Bulvarno-Kudriavska Str., 04053, Kyiv, Ukraine, http://orcid.org/0000-0003-1415-0504, e-Mail: a.shpyrka@kubg.edu.ua

**Borys Grinchenko Kyiv University, 18/2, Bulvarno-Kudriavska Str., 04053, Kyiv, Ukraine, https://orcid.org/0000-0001-6913-2448, e-Mail: l.bondarenko@kubg.edu.ua

***Borys Grinchenko Kyiv University, 18/2, Bulvarno-Kudriavska Str., 04053, Kyiv, Ukraine, orcid. org/0000-0002-5035-4355, e-Mail: h.kondratenko@kubg.edu.ua

****Borys Grinchenko Kyiv University, 18/2, Bulvarno-Kudriavska Str., 04053, Kyiv, Ukraine, orcid.org/0000-0002-1855-1236, e-Mail: o.shpyrka@kubg.edu.ua

DOI 10.12975/rastmd.20219211 Submitted October 17, 2021 Accepted December 6, 2021

\begin{abstract}
The article dwells on the results of an experimental test of the levels of formation of emotional expressiveness of future vocalists. A theoretical analysis of Ukrainian and foreign scientific literature is carried out to define the concept of "emotional expressiveness of a vocalist". The article clarifies the essence and structure of the vocalist's emotional expressiveness. The survey, testing, and observation were used as the main methods in the experiment. The article dwells on an experimental test of the levels of formation of emotional expressiveness of future vocalists. A theoretical analysis of Ukrainian and foreign scientific literature is carried out to define the concept of the "emotional expressiveness of a vocalist." The article clarifies the essence and structure of the vocalist's emotional expressiveness. It is analyzed in motivational and value, cognitive and analytical, emotional and empathic, practical and creative dimensions. Authors have defined the following methodological approaches to the analysis of the formation of emotional expressiveness of the vocalist: axiological, interdisciplinary, and competence-based approaches. Researchers have developed criteria and indicators for the formation of structural components of the vocalist's emotional expressiveness. An ascertaining experiment was carried out to find out the levels of formation of vocalists' emotional expressiveness. The survey, testing, and observation were used as the main methods in the experiment. The total number of respondents for the ascertaining experiment is 391 people. Students of 1-4 years of the first (Bachelor's) level of specialties "Musical Art" of the educational and professional programs 025.00.01 Musical Art and 025.00.02 Solo Singing. As a result of the experiment, researchers found that the emotional expressiveness of students is at an average level, so it is necessary to improve it.
\end{abstract}

\section{Keywords}

emotional expressiveness, emotional expressiveness of the vocalist, structural components of the emotional expressiveness, axiological approach, competence-based approach

\section{Introduction}

In modern society musical art develops and transforms as a means of influencing the formation of the individual, an activator of its cultural development. The powerful communicative ability of musical, in particular vocal performance, opens up new ways for scientific research because vocal art is constantly being transformed depending on the needs of the modern world. Effective means 
of emotional communication between the performer and the audience are musical and vocal expressiveness. Both are nonverbal channels that rely on acoustic signals to transmit messages. It is this branch of art that carries a direct emotional communication between the performer and the audience, which affects a person's consciousness, forming refined artistic tastes and expanding the worldview. Modern vocal pedagogy needs to "revise" established stereotypes and establish new paradigms that would allow the relevant educational structures to develop the singer in both speech and vocal technique; in a universal control system for all parameters of quality sound, relating to the range, resonators, volume, work of the articulatory apparatus, intonation, expressiveness, vocal-musical (motor) hearing, both in academic singing and in folk, pop and melodic declamation manners of voice formation, etc. (Folomeeva, 2012).

The predominance of emotional factors in musical art requires purposeful development of the emotional sphere of students. Therefore, there is a raising issue of training future vocalists capable of emotional communication with the public, ready to implement the main task of vocal art - the embodiment of the artistic image of a musical work, through perfect vocal technique, possession of musical means of expression, transmitting the appropriate emotional state to the public to receive their emotional feedback. We consider emotional expressiveness as one of the main factors in the formation of a future vocalist. Thus, the formation of emotional expressiveness of the performance becomes particularly important in the professional training of the future vocalist, since the interpretation of the work requires not only accurate reproduction of the composer's idea by musical means but also the transmission of various psychological states, feelings, and emotions. According to the authors of the study, the emotional expressiveness of the student's performance involves a deep immersion in the content of the vocal work to understand the protagonist's emotional state. This can be facilitated by the future vocalist's own emotional experience, level of mastery of vocal skills, and technical means of expression. The reincarnation of the vocalist and the transmission of emotional impulses, communication in the language of emotions with the audience requires some training. The question arises about teaching future vocalists and what methods to form emotional expression in solo singing.

Psychologists consider emotional expressiveness within the framework of the theory of the signal function of emotions. V. Nikandrov defines emotional expressiveness as a property of an individual that reflects his tendency and ability to vividly manifest his affective experiences in external behavior. In this property, the signal function of emotions is realized (Nikandrov, 2009, pp.503504).

In his psychological research, Patrik N. Juslin calls the concept of "emotional expressiveness" (emotional expression) a questioner. "In one sense, the term "emotional expression" is slightly misleading: it is only sometimes that musicians are truly expressing their own emotions in a composition or performance. What is usually meant by the term emotional expression is that 
listeners perceive emotional meaning in music" (Juslin, 2013, p.1). In his research, the scholar explores exact types of emotional content, which can be transmitted in music and offers a multi-layered conceptualization of the expression of emotions in musical art.

O. Yeroshenko in the studies of a range of issues related to the emotional sphere of vocal art defines emotional expressiveness as one of the most important characteristics of the performing work of a singer and actor, the parameters of which depend on the transformations of various emotional and psychological movements, creative nuances in the singing process (Yeroshenko, 2008, p.4). The scholar specifies the interaction of psychophysiological (emotional sphere) and solely performing aspects of the singer and actor's work.

Myriam Albor expresses quite a different opinion from scholars in other fields regarding emotional expressiveness in music: "I will argue that, even though the movements in music associated with musical expressiveness might not necessarily be associated with emotions, they might very well be associated with certain feelings of the movement itself." (Albor, 2016, p.37). Thus, the scholar denies the direct connection of nonverbal signals determined by musical expressiveness with emotions and the emotional expressiveness of the performer.

\section{Problem of Study}

The study of the problems of vocal performance from the point of view of emotional content, namely the problem of forming emotional expressiveness in the training of vocalists in higher education institutions, is not yet sufficiently covered in the domestic scientific literature.

The lack of research on the phenomenon of emotional expressiveness in the field of vocal training encourages us to search for a solution to the issue of methodological support for the educational process, taking into account the aspects of the formation of emotional expressiveness of the vocalist. The purpose of our research is to experimentally test the state of formation of emotional expressiveness of future vocalists. Therefore, the tasks are: implementation of a theoretical analysis of the concept of "emotional expressiveness" in the scientific literature to substantiate the core of the concept of "emotional expressiveness of a vocalist", defining its structural components, covering and analyzing results of a diagnostic experimental cross-section of the levels of formation of emotional expressiveness of a vocalist.

\section{Methods}

\section{Research Model}

The research methodology is based on general theoretical and methodological provisions of Philosophy, Psychology, Pedagogy, and Musicology.

The study of theoretical and practical works, the use of the dialectical method in research concerning the professional training of future vocalists, allowed us to identify a number of contradictions between:

- The objective need of modern society for competitive specialists and the real state of training of vocalists, focused on the formation of functional readiness of 
graduates of art institutions of higher education;

- The availability of scientific research on the problems of professional training of the future vocalist in solo singing classes and the lack of a methodological model for the formation of emotional expressiveness skills;

- Traditional methods of working with vocalist students and features of forming emotional expressiveness;

- The need for the purposeful formation of emotional expressiveness of the future vocalist and the lack of appropriate methodology.

This made it possible to understand the objective dialectic of forming the emotional expressiveness of a vocalist from the standpoint of axiological, interdisciplinary, and competence approaches. Hence, the process of preparing a student to form emotional expressiveness should be built on the basis of:

- Axiological approach in the context of the formation of the axiosphere of the student's personality (stable positive personal and social motivation to achieve a certain creative goal, revealing the potential of their own emotional sphere, the source of which is a system of universal values, value attitude to works of musical art and vocal and performing activities, the vocalist's awareness of self-worth in the cultural enrichment of society) (Tkach and Oleksiuk, 2021).

- An interdisciplinary approach that allows the versatile development of the future vocalist through the involvement of knowledge from other scientific fields and academic courses to improve professional training (interaction of many psychological and pedagogical, music and theoretical, and vocal and performing courses).

- Competence-based approach, which provides for a practice-oriented process of students' professional training to achieve the planned result, combines relevant knowledge, skills, practical experience, and personal qualities, which ensures future productive professional vocal and performing activities.

Clarification of the categorical apparatus became possible due to the application of the law of reflection of reality in thinking and a number of dialectical ways of cognition (analysis and synthesis, logical method, generalization and comparison, systematization of philosophical, psychological, pedagogical, musicological literature).

\section{Participants}

To find out the state of formation of emotional expressiveness of the vocalist, experimental work was carried out. We developed diagnostic tools - criteria, indicators, and levels of formation of emotional expressiveness of the vocalist. An ascertaining experiment was carried out in order to find out the initial level of formation of emotional expressiveness of the vocalist. The total number of surveyed for the ascertaining experiment is 391 people. Among them, there are students of 1-4 courses of the first (Bachelor's) level of specialties "Musical Art" of educational and professional programs 025.00.01 Musical Art and 025.00.02 Solo Singing. 


\section{Data Collection Tools}

During the ascertaining experiment, the following research methods were used: sociological methods of survey, questionnaire, testing, as well as creative and educational tasks, pedagogical observation, analysis of the results of the activities of future vocalists.

We evaluated using the methodologies: Methodology of T. Ehlers "Personality Diagnostics for Motivation to Succeed". The methodology consists of 41 questions and an answer form, where the recipient must answer only "Yes" or "No", based on their inner feelings. The results are processed using the Answer Key, where the match with the key equals 1 point. As a result, we get an answer on a scale: low, average, moderately high, or too high level of motivation to succeed.

Methodology "Scale for Assessing the Need for Achievement" by Orlova Yu.M., which is suggested by Hryn (2014). The questionnaire contains 22 "Yes-No" questions related to future prospects, self-confidence, favorite work. The result is deciphered by the key.

Methodology of "Value Orientations" by $M$. Rokeach (1973, pp.112-114). The method was used to diagnose the formation of a system of universal values and their hierarchy among vocal students. Accordingly, students are presented with two lists of values: terminal values (the belief that the ultimate goal of individual existence is worth striving for) and instrumental values (the belief that a certain course of action or personality trait is preferable in any situation). In the lists, students assign a rank number to each value, and put the cards in order of their subjective personal significance.
Methodology "Diagnostics of the Level of Empathy" by V. Boyko. The questionnaire consists of 36 statements that contain certain markers of empathic experiences and abilities. If the interviewee agrees with the statement, then he puts a plus sign in the answer form, and if he does not agree - a minus sign. A key is attached to the answer form, which consists of six scales with answer numbers. Indicators of individual scales from 0 to 6 points are analyzed and indicate the significance of a particular parameter (channel) in the structure of empathy."

Pashukov's methodology "Research of Emotional Responsiveness" is a modified test - questionnaire of empathic tendencies developed by A. Mehrabian and N. Epstein. The test questionnaire has 33 statements that reflect certain situations that can cause sympathy, empathy when communicating and interacting with people, products of their activities, living and inanimate nature.

The methodology "Study of the Emotional Sphere" involves 26 "Yes No" questions. To process the results, we used a key that helped us assess the level of emotionality in the points. Depending on the range of points, there are three blocks of characteristics of the level of emotionality: from 13 to 26 points - a healthy attitude to emotions, sometimes it is not a shame to show your feelings; from 4 to 12 points -knows how to show your emotions but prefers not to show them; 3 points and less - a very reserved person.

\section{Scale}

\section{Comprehensive test}

Comprehensive test "Possession of Vocal 
Terminology" (Shpyrka), which consists of 6 blocks. This test is structured based on using general concepts of vocal terminology (based on encyclopedias). The first block involves multiple choice answers for definitions "sound thinning", "white sound", "diaphragm". The second block involves matching the concept ("arioso", "aria”, "arietta”, "vocalization") and its definition. In the third block, the interviewee must match the singer's voice and its characteristics, for example, characteristics for such voices as mezzo-soprano, soprano, tenor, contralto, lyrical baritone, baritone, bass, bass profundo. The fourth block includes answering questions about the features of the voice apparatus, and the fifth block includes filling missing words into the definitions of such concepts as vocal cords, sound attack, and voice apparatus. Unlike the previous blocks, the sixth one provides for a written response (personal vision) by students of the concept of emotional expressiveness of the vocalist.

\section{Diagnostics of Creative Potential and Creativity}

Test "Diagnostics of Creative Potential and Creativity" (Rogov, 1999). The test "Diagnostics of Creative Potential and Creativity" consists of 18 multiple-choice questions. For each answer, a certain number of points are awarded according to the key. According to the test results, creative potential and creativity are interpreted in two directions. If the interviewee scores 48 or more points, he has significant creative potential, which provides a wide variety of creative opportunities. If the interviewee scores 18 - 47 points, he has qualities that allow him to create, but there are also some barriers.

\section{Pedagogical Observation}

Pedagogical observing the educational and performing activities of students and analyzing concert and academic performances of students of the experimental group during the academic year. While observing the concert performances of students, we focused on the following features: stage image, mastery of vocal and performing skills, performance confidence, concentration, embodiment of the artistic image of the work, audience reaction, etc.

\section{Results}

Nowadays scholars have created a database of experimental studies related to the study of the acoustic properties of vocalists' voices, the correspondence of the perception of emotional signals by listeners (viewers), the features of the emotional expressiveness of the vocalist's voice in the recording and during a public performance, etc. (Kotlar and Morozov, 1976; Romanenko, 2012; Juslin, 2013; Laukka, 2017; Hyunsin and Chang, 2010.)

Foreign researchers study the problem of emotional expressiveness of performers in many aspects of this multi-vector problem (Thompson (2010) (the role of facial expressions in vocal emotional communication), Humrichouse (2010) (on the hierarchy of the structure of emotional expressiveness), Russell, Bachorowski and Fernandez-Dols (2003) (fascial and vocal expression of emotions), Robinson and Hatten (2012) (a study of emotions in music) and Eerola, Friberg and Bresin (2013) (emotional expressiveness in music), Dahl and Friberg (2007) (visual perception of expressiveness in musicians' body movements) more deeply. 
The problem of emotional expressiveness has been studied by Ukrainian and foreign psychologists, linguists, musicologists, and physiologists, but theoretical analysis of research has shown that there is no single definition of the concept. For our research, it is necessary to substantiate the concept of "emotional expressiveness of a vocalist", which in turn provided for the study of domestic and international scientific research on this issue.

The analysis of various scientific sources gives grounds to identify scientific areas in which we find the study of the concept of "emotional expressiveness", namely: Psychology, Musicology, and Pedagogy. There are several areas of research on the formation of emotional expressiveness.

Shawn Michael Condon, a proponent of the practice-oriented theory, researches the emotional expressiveness of a vocalist in his activities. The author claims that most studies of the problem of emotional expressiveness are based on the perception of the listener, his ability to perceive the emotional message of the performer, but do not demonstrate this topic through understanding the performer himself (Condon, 2018) (Figure 1).

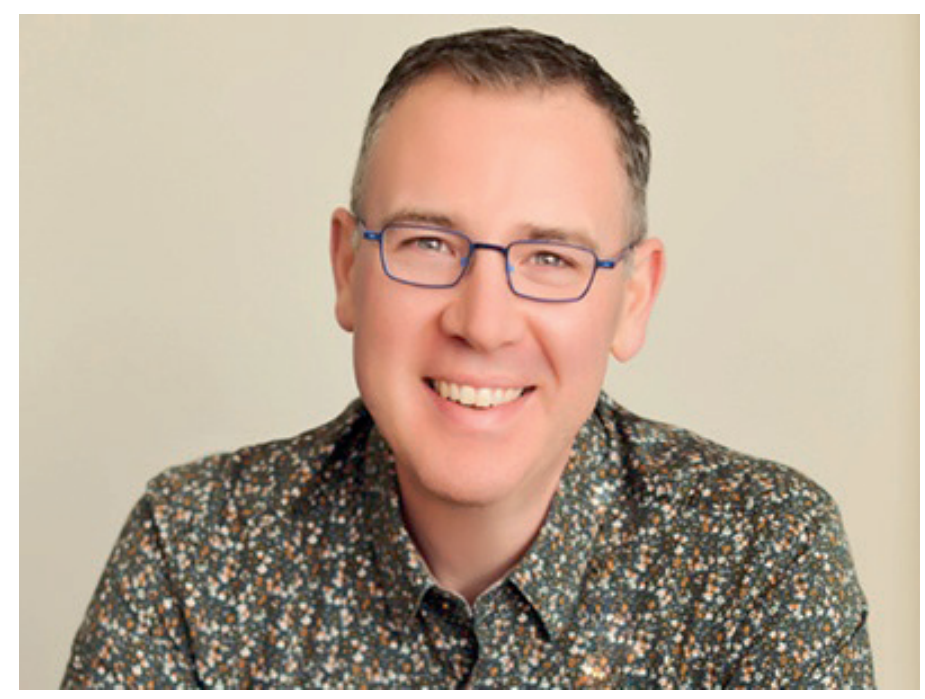

Figure 1. Shawn Michael Condon

In his research, the author reveals the features of the formation of emotional expressiveness of the performer, explores ways of its formation in practice. The result of his research was the definition of a three-stage model of skill acquisition, taking into account the specific needs of singers, such as the development of skills of emotional connection with the text, improvement of character traits, emotional communication through body language and facial expression.
Proponents of the theory of nonverbal communication scholars Heidi R. Riggio and Ronald E. Riggio define emotional expressiveness as follows: "Emotional expressiveness" is often used to denote skill in sending messages nonverbally and facially. The "expressive" person is the individual who is high in emotional encoding ability; that is, he or she can accurately nonverbally communicate what he or she is feeling" (Riggio \& Riggio, 2002, pp.195-196). Thus, the authors 
claim that a person is able to nonverbally transmit their internal emotional states, which explains and makes possible the mechanism of emotional communication between a vocalist and the public through nonverbal communication, which is important for our research.

Understanding emotional expressiveness through the prism of nonverbal communication is also seen in social psychology research. Friedman, Prince, and Riggio described emotional expressiveness as a general expressive style, also called nonverbal expressiveness, and experimentally researched the problem of understanding and evaluating nonverbal expressiveness. Scientists note that there is a problem of ambiguity in the definition of expressiveness in various researches: “... during the past decade, two additional factors have limited the study of expressiveness. The first factor is a certain degree of conceptual ambiguity. Expressiveness has been used to mean different things including acting ability, natural sending ability, communication ability, emotionality, femininity, extraversion, responsivity, and empathy" (Friedman et. al., 1980a, p.334). Emotional expressiveness exists in different spheres of life, so it is difficult for scholars to come to a unified definition of the concept.

In turn, the Ukrainian scholar M. Shpak considers this issue in the pedagogical dimension. In our opinion, the scholar is a follower of the theory of nonverbal communication in combination with the signal function of emotions. He further develops ideas of his foreign colleagues and defines emotional expressiveness as: "external or internal manifestation of emotional experiences, where external (expressive) expression of emotions and feelings occurs with the help of facial expressions, pantomimes, gestures, intonation of speech, general features of behavior" (Shpak, 2009, p.51). That is, in addition to nonverbal means, the scholar also adds speech, because, in vocal art, music is closely related to the poetic text, intonation, and rhythm of pronunciation.

\section{Results of Literature Analysis}

The literature analysis made it possible to generalize theoretical provisions on emotional expressiveness in the research of Ukrainian and foreign scientists and suggest the following definition of the concept:

The emotional expressiveness of a vocalist is an individual ability to model and deliver (relay) emotional states programmed in a vocal work of art, using the vocal capabilities of the performer, nonverbal signals, and means of musical expression. It involves deep immersion in the content and artistic image of a vocal work, in order to understand the emotional state of the main character, taking into account the vocalist's own emotional experience, the level of proficiency in vocal skills, and technical means of expression.

The next task of our article is to determine the structure of the concept of emotional expressiveness of future vocalists.

There are several vectors for studying the structure of emotional expressiveness. The first one considers outlining the structure of emotional expressiveness through the construction of a 
hierarchical model. J. J. Humrichouse, in his work, describes the attempts of scholars to structure the phenomenon of emotional expressiveness and build a hierarchical model of the structure. The author analyzes different approaches to understanding the structure and defines it as follows: "Emotional expressivity has been modeled at different levels of abstraction including at a general factor level, a dimensional level, and a discrete emotions level; however, currently there is only limited support for a hierarchical model that integrates these different levels of abstraction" (Humrichouse, 2010, p.1). This experimental study in Psychology allowed the scientist to integrate existing models into the field of emotional expressiveness and confirm a three-level hierarchical model.

The second vector is characterized by the vision of the structure through the identification of three key aspects of emotional expressiveness: "Emotional Expressivity-comprised of Positive Expressivity, Negative Expressivity and Impulse Intensity-as a separate model in these data" (Gross \& John, 1997). This study demonstrates the importance of a diversified approach to the study of emotional expressiveness and determines it in line with the signaling function of emotions.

Trierweiler's study is of great importance in our research. It examines the structure of emotional expressiveness by measuring certain emotions, such as: love, joy, fear, anger, shame, and sadness (Trierweiler et al., 2002). Such a basic set of emotions for vocal performance is most often found in studies of the emotional expressiveness of vocal speech. This is due to the peculiarities of the emotional content of the works, and also narrowing the range of researches to find out the features of the expression of each of these emotions.

Based on the study, comparison and generalization of scientific literature on the structure of emotional expressiveness, we have suggested the following structural components of emotional expressiveness of the future vocalist: motivational and value, cognitive and analytical, emotional and empathic, practical and creative components. Let us take a closer look at these components

The motivational and value component of the vocalist's emotional expressiveness provides for positive personal and social motivation of the vocalist to achieve a certain creative goal and the vocalist's awareness of the value of his own vocal and performing activities in the cultural enrichment of society, provides an internal rethinking of the future vocalist's own emotional experience, assessment of energy resources and emotional reserves, which motivate and activate the process of forming the emotional expressiveness of the vocalist.

The motivational and value component of the vocalist's emotional expressiveness comprises a value attitude to vocal and performing activities, a stable positive motivation for educational and cognitive activities, the ability to independently master knowledge about emotions in vocal art, the organization of the process of independent work for the implementation of the program of their own self-development, the desire to improve vocal skills for successful performing activities, awareness of 
the value of vocal art for the cultural heritage of society.

The cognitive and analytical component of a vocalist's emotional expressiveness involves the accumulation of knowledge about the essence, structure, and mechanisms of emotions in the process of vocal training and performance. This encourages the future vocalist to study the states and reactions of the body while singing, search for information on self-regulation of emotional and physical sensations, increases his interest in finding an example or sharing experience with experienced performers, contributes to the accumulation of a complex of vocal knowledge and skills to expand his perception of the world and emotional experience.

An important condition for acquiring knowledge and skills is the mastery of reflexive skills by the future vocalist. Reflection in vocalist training allows them to analyze both their own mistakes and achievements, as well as the mistakes of other vocal students.

So, the cognitive and analytical component provides the accumulation of knowledge about the mechanism of occurrence of emotions, the features of the indication of emotions through nonverbal means, the possibility of stage embodiment and concentration of attention on the emotional dimension of the performance, reflection of one's own activities.

The emotional and empathic component of the vocalist's emotional expressiveness is focused on acquiring the ability to analyze emotions associated with the educational, performing, and creative activities of the future vocalist. This component also involves mastering the elements of empathic communication with the audience, evaluating one's own achievements; independently understand the emotional content of vocal work and its justified usage in stage embodiment.

Empathy for a future vocalist is not only the ability to take on the role of another person but also an intuitive understanding of the character's psychological mood and hidden motives. To feel the spiritual tosses, the slightest movements of someone else's soul through the identification of their feelings with the emotions of another person, but with the awareness of their exclusivity and individuality.

The practical and creative component of a vocalist's emotional expressiveness involves the future vocalist using means of emotional expressiveness in his rehearsal and concert activities, which include the emotional expressiveness of voice, facial expressions, body (movements and gestures), gaze, pronunciation, and articulation.

The formation of emotional expressiveness of the future vocalist requires him to include elements of creativity in this process.

This component determines the level of ability to independently embody the artistic and figurative content of the work through the use of means of emotional expressiveness. The practical and creative component of the emotional expressiveness of a vocalist provides for the necessary level of integrated knowledge of skills and abilities to 
solve professional problems, creative manifestations in vocal and performing activities and the ability to creatively apply the acquired skills and knowledge, the effectiveness of independent training depending on the goals set.

\section{Quantitative Research Results}

We organized and carried out an ascertaining experiment to determine the levels of formation of emotional expressiveness of students in Solo Singing, Voice Production, and Vocal classes. The bases for the ascertaining experiment were the Borys Grinchenko Kyiv University, the Volodymyr Vynnychenko Central Ukrainian State Pedagogical University, and the National Pedagogical Dragomanov University. The total number of surveyed for the ascertaining experiment is 391 people. Among them, there are students of 1-4 courses of the first (Bachelor's) level of specialties "Musical Art" of educational and professional programs 025.00.01 Musical Art and 025.00.02 Solo Singing.

The main objectives of the ascertaining experiment were as follows:

- To develop and substantiate a system of criteria and indicators for determining the formation of emotional expressiveness of future vocalists in solo singing classes;

- To determine the levels of formation of emotional expressiveness of future vocalists in solo singing classes;

- According to the identified criteria and indicators, find out the state of formation of emotional expressiveness of students.

For pedagogical diagnostics of the levels of formation of emotional expressiveness of future vocalists, we have developed a system of criteria and indicators:

\section{Motivational and value criterion}

- The degree of awareness of the motives for improving vocal and performing activities for successful professional development;

- The degree of awareness of the need for personal growth and self-improvement to achieve the goal;

- The degree of focus on universal and vocal-performing values.

Cognitive and analytical criterion:

- The degree of knowledge of concepts and terminology, using methods and skills of vocal and performing activities; the degree of the ability to evaluate

- Personal educational, performing, and cognitive activities for further selfimprovement.

Emotional and empathic criterion. We define the criterion indicators as follows:

- The degree of mastering empathy skills;

- The degree of the ability to be emotionally responsive;

- The degree of formation and stability of the emotional sphere.

Practical and creative criterion:

- The degree of the formation of special vocal skills;

- The degree of mastering specific means of emotional expressiveness; 
- The degree of expression of students' creative manifestations and creativity necessary for the performance of future vocalists.

We have determined the following levels of formation of emotional expressiveness in accordance with the criteria and indicators: creative, productive, and reproductive levels.

The creative level of formation of the future vocalist's emotional expressiveness means the ability to show empathy, with a clearly expressed motivation and desire to achieve success. Values act as a driving force for the implementation of vocal and performing activities. Thanks to their knowledge and skills, students do not experience difficulties in applying them into practice, which is necessary for successful performance activities and the implementation of the artistic image of the work. All indicators are harmoniously combined and focused on emotional communication with the public. A separate indicator of the creative level of the emotional expressiveness formation is the creative vision of students' own stage image, interpretation and emotional transmission of the vocal and emotional content of the work, understanding its deep content through independent research of the history of writing and performing the work, interest in knowledge on the emergence of emotions, self-regulation of emotional states and emotional response of the audience.

The productive level is manifested by a permanent interest in the process of forming emotional expressiveness. Students have expressed vocal and performing skills, but empathic abilities and motivation for success are not sufficiently expressed. At this level, there are difficulties in applying vocal skills and abilities in practice, as well as average indicators of creative potential and creativity. This affects the stage transformation, causes uncertainty and discomfort at the time of a public performance, and disrupts the process of embodying the artistic image of the work. Value orientations do not reflect the vocalist's desire for emotional communication with the audience.

The reproductive level is manifested by low indicators of general vocal training, empathy, motivation, value attitude to one's activities, and vocal art, which causes the problem of developing vocal skills. It is characterized by a low ability of the future vocalist to stage embodiment, lack of motivation for success and self-improvement. This leads to problems and mistakes during public performance. It is difficult to think about the emotional content of the work and the embodiment of an artistic image, if there are no basic skills in controlling the activity of the vocal and performing apparatus, which affects the creative process, puts an emotional framework for the vocalist.

The program of the ascertaining experimental study was developed taking into account these criteria and indicators. To assess the levels of formation of motivational and value, cognitive and analytical, emotional and empathic, practical and creative components of the emotional expressiveness of the future vocalist, appropriate diagnostic methods were selected and developed. 
Theme 1. Level of formation of the motivational and value component of emotional expressiveness

The level of formation of the motivational and value component of emotional expressiveness according to the indicator "a measure of awareness of the motives for improving vocal and performing activities for successful professional development", we evaluated using the methodology of T. Ehlers "Personality Diagnostics for Motivation to Succeed".
We present the processed data for 391 recipients as a percentage (Figure 2), which clearly shows that: $58,8 \%$ of respondents have a moderately high level of motivation, 23,5\% -too high, $11,8 \%$ - average, and 5,9\% -low. This proves that the surveyed students tend to have a moderately high level of motivation for success, which will qualitatively influence the process of forming emotional expressiveness, because they are interested in their own creative and professional growth.

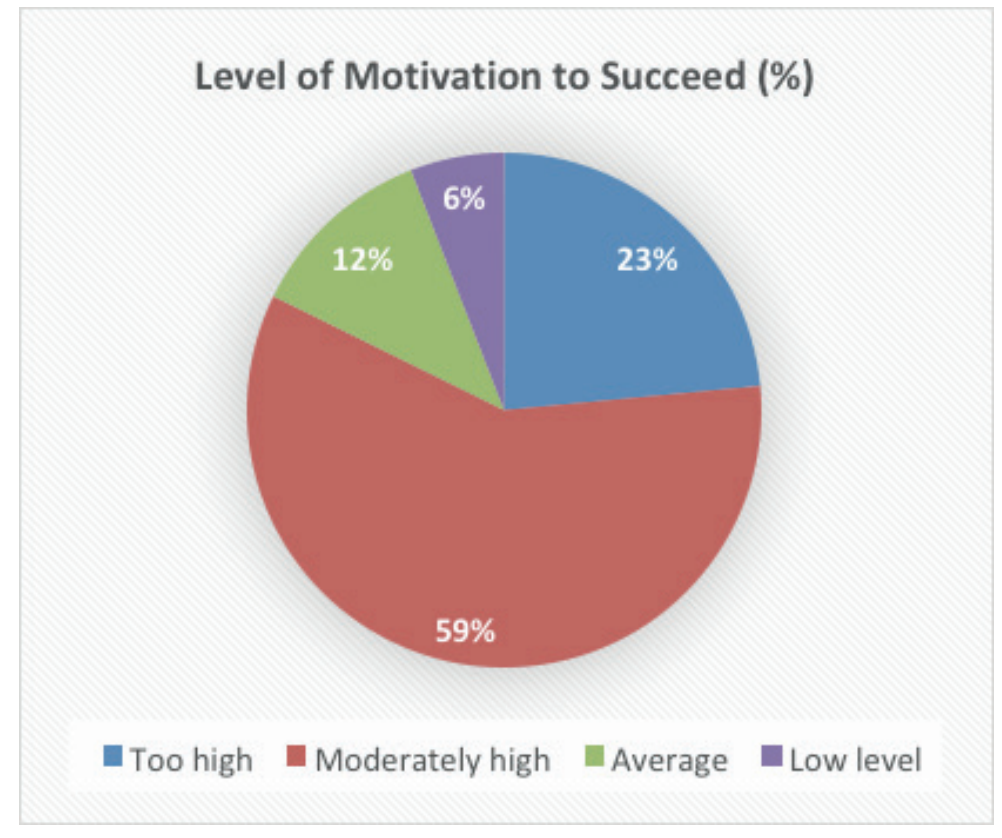

Figure 2. Level of motivation to succeed

The level of formation of the motivational and value component of emotional expressiveness according to the indicator "the degree of awareness of the need for personal growth and selfimprovement to achieve the goal", we evaluated according to the methodology "Scale for Assessing the Need for Achievement" by Orlova Yu.M., which is suggested by Hryn (2014).

Responses are expressed in levels: low, average, and high, which in turn are divided into subcategories (each level has 3 subcategories that express the intensity of the characteristic). The results for 391 recipients are expressed as a percentage (see Figure 3). Measuring the need for achievement shows that $47,1 \%$ of respondents have a low level of need for achievement, 35,3\% have an average level, and only $17,6 \%$ have a high level of need for achievement. 


\section{The Level of Need for Achievement (\%)}

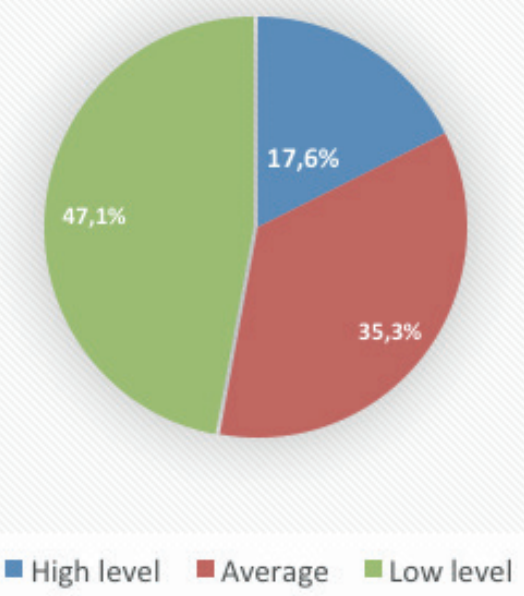

Figure 3. Level of need for achievement

The level of formation of the As a result, $11.8 \%$ of respondents motivational and value component of demonstrated a high level of awareness emotional expressiveness according of musical and pedagogical values, an to the indicator "focus on universal average level was demonstrated by and vocal and performing values" was $88.2 \%$ of students, a low level was not studied using the methodology of "Value demonstrated (0\%) (Figure 4). Orientations" by M. Rokeach (1973, pp.112-114).

The Level of Value Orientations (\%)

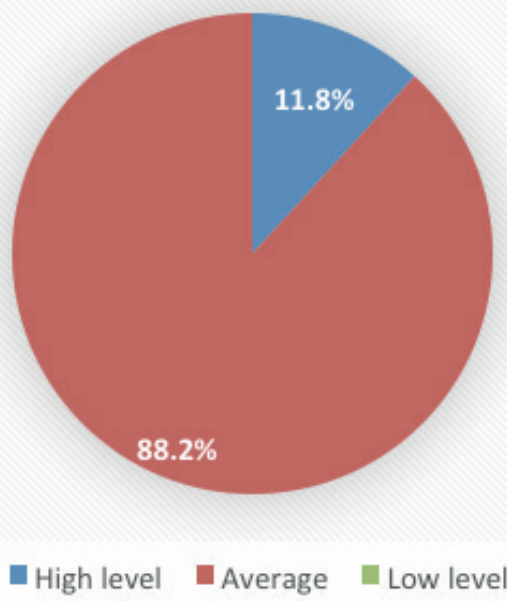

Figure 4. Level of value orientations 
Evaluating the results, we can conclude that the level of formation of the motivational and value component of emotional expressiveness is mainly average. Special attention should be paid to correcting the level of need for achievement and the level of value orientations of future vocalists. Interestingly, students' motivation for success is at a high level, which will give an impulse to further improvement.

\section{Theme 2. Level of the cognitive} and analytical component of the vocalist's emotional expressiveness The next block was a survey on the formation of the cognitive and analytical component of the vocalist's emotional expressiveness.

Diagnostics of the formation of the cognitive and analytical component of the studied phenomenon according to the indicators "the degree of knowledge of concepts and terminology, using methods and skills of vocal and performing activities", the degree of ability to apply the acquired knowledge and skills in their creative activities", "degree of the ability to evaluate their educational, performing and cognitive activities for further self-improvement" was carried out using a comprehensive test "Possession of Vocal Terminology", which consists of 6 blocks.

The test results show that the level of proficiency in basic vocal terminology of the surveyed students of various courses of the specialty Musical Art of educational and professional programs Musical Art and Solo Singing in most cases does not exceed $70 \%$ and most often is only $25-58 \%$. This indicates a lack of awareness of recipients, which will affect the successful implementation of performing activities of future vocalists.

Theme 3. Level of formation of the emotional and empathic component of the emotional expressiveness

The next block of our experimental research aims at determining the level of formation of the emotional and empathic component of the emotional expressiveness of the future vocalist. It involves attracting and strengthening the emotional essence of the vocalist, which has been given him by nature. A high level of empathy, emotional responsiveness, and emotionality allows the performer to share emotions with the audience, find ways to transmit them, and empathize with the musical character. But emotionality can also negatively affect concentration, attentiveness, the ability to abstract and be calm during rehearsals and concert performances.

The level of formation of the emotional and empathic component of the emotional expressiveness of the future vocalist according to the indicator "level of mastering empathy skills", we assessed using the method "Diagnostics of the Level of Empathy" by V. Boyko (Zelinska \& Mykhailova, 2009).

We were interested in the overall level of empathy, which is interpreted at four levels: very low, below average, average, and very high. For the group of students we interviewed, the result is listed as a percentage (see Figure 5). It turned out that a very low level of empathy is observed in $11.8 \%$, below the average in $47.1 \%$, an average in $35,3 \%$, and very high only in $5,8 \%$ of respondents. 


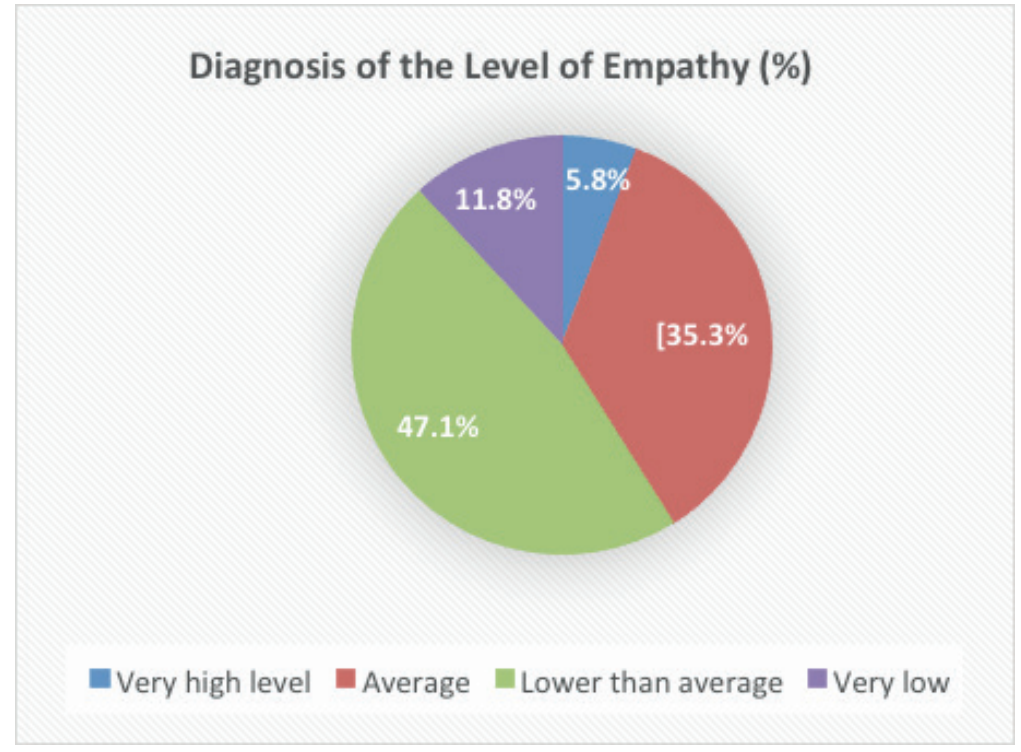

Figure 5. Level of empathy

The next stage of the survey is to The interpretation of the answers may determine the level of formation of the be different for women and men because emotional and empathic component of young men often hide their feelings. The the vocalist's emotional expressiveness survey results show that $58,8 \%$ of the by the indicator "measure of the ability students surveyed have a low level of to emotional responsiveness" which emotional responsiveness, $23,5 \%$ have was carried out using the methodology an average level, and only $17,7 \%$ have a "Research of Emotional Responsiveness" high level (Figure 6).

by Pashukov (Zelinska \& Mykhailova, 2009).

The Level of Emotional Responsiveness \%

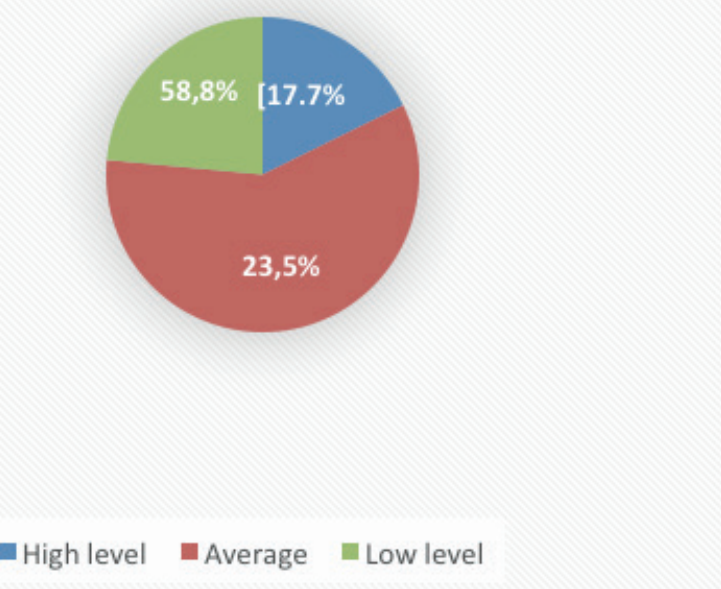

Figure 6. Level of emotional responsiveness 
Also, we assessed the formation of the emotional and empathic component of emotional expressiveness according to the indicator "degree of formation and stability of the emotional sphere" using the questionnaire "Study of the Emotional Sphere" (Zelinska \& Mykhailova, 2009).

As a result, it was found that $94,1 \%$ of respondents have a high level of emotionality and a healthy attitude to emotions. Only $5,9 \%$ of recipients consider it necessary not to show their feelings and none of the students were very reserved people. This proves that future specialists studying the creative professionals are more able to express their emotions, but at the same time, they are emotionally unprotected, more susceptible to negative influence and manipulation (Figure 7).

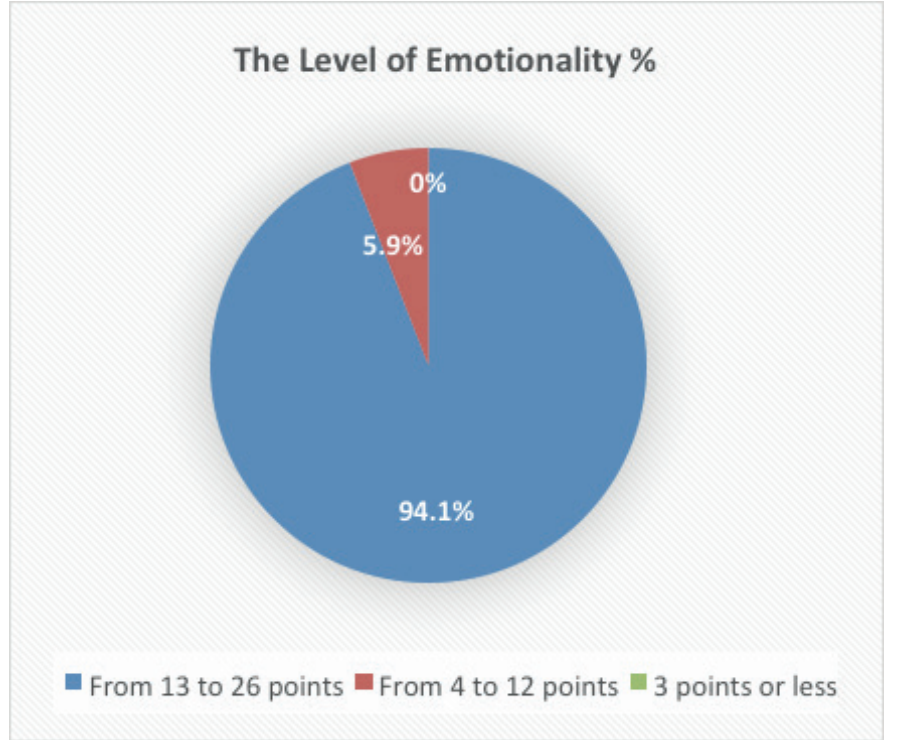

Figure 7. Level of emotionality

The results of a diagnostic cross-section of the level of formation of the emotional and empathic component of the vocalist's emotional expressiveness indicate that the recipients are very creative and have a high level of emotionality. According to the test, $94 \%$ of respondents have a healthy attitude to emotions and do not hesitate to show them to others.

Theme 4. Level of formation of the practical and creative component of the vocalist's emotional

\section{expressiveness}

The next block of diagnostics is to determine the level of formation of the practical and creative component of the vocalist's emotional expressiveness.

We defined the level of formation of the practical and creative component according to the indicators "the degree of formation of special vocal skills and abilities of students", as well as "the level of mastering specific means of emotional expressiveness" by observing the educational and performing activities of students. Observation shows that $60 \%$ of senior students have a broader set of tools for regulating 
their own emotional state during speech and emotional communication with the public. They consciously use their vocal and performing skills to embody the imaginative content of the work, control the situation, and use their skills to get an emotional response from the audience. This is due to a significant vocal, performing, and emotional experience. We also found that $20 \%$ of students hyperbolize, overplay emotionally, which negatively affects the emotional perception of viewers. Such performers capture the main emotional content of the work and reproduce it with the help of vocal and performing skills, without demonstrating their own perception, without embodying into the image of the main character.

The level of formation of the practical and creative component according to the indicator "the degree of creative disposition of students and manifestations of creativity necessary for the performance of future vocalists", we assessed using the test "Diagnostics of Creative Potential and Creativity" (Rogov, 1999).

The most dangerous barrier is fear, especially for people who are focused on mandatory success (Figure 8 ).

\section{Level of Creative Potential and Creativity \%}

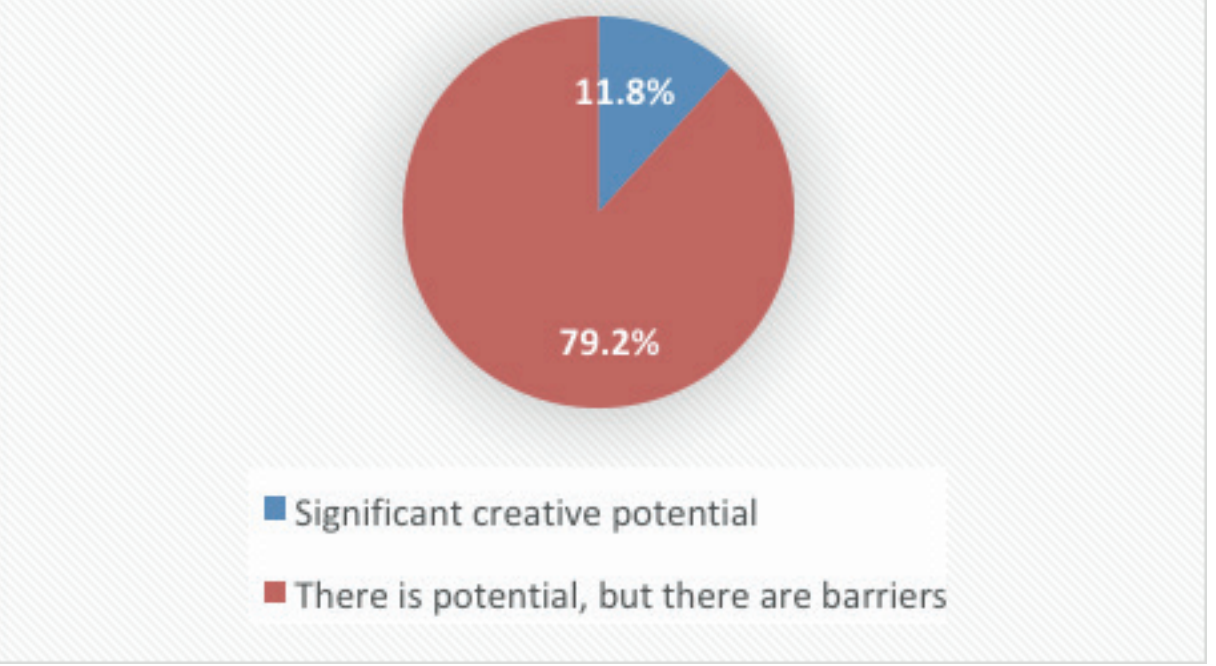

Figure 8. Level of creative potential and creativity

The results obtained prove that recipients have creative potential, but some factors prevent them from fully realizing it (for example, fear, such as fear of failure or judgment, lack of self-confidence). Often, society and its judgment are the main factors in inhibiting creative potential and creativity. Therefore, during the formation of a practical and creative component, the main task of a teacher is to suggest the implementation of an idea, to give an opportunity to create something new on your own. Consequently, only $11.8 \%$ of recipients have significant creative potential and are able to realize it. 
As a result of calculating the percentage in the diagram "Levels of Formation of of the level of formation of emotional Emotional Expressiveness of a Vocalist"( expressiveness among 391 respondents, Figure 9). we get the following results, represented

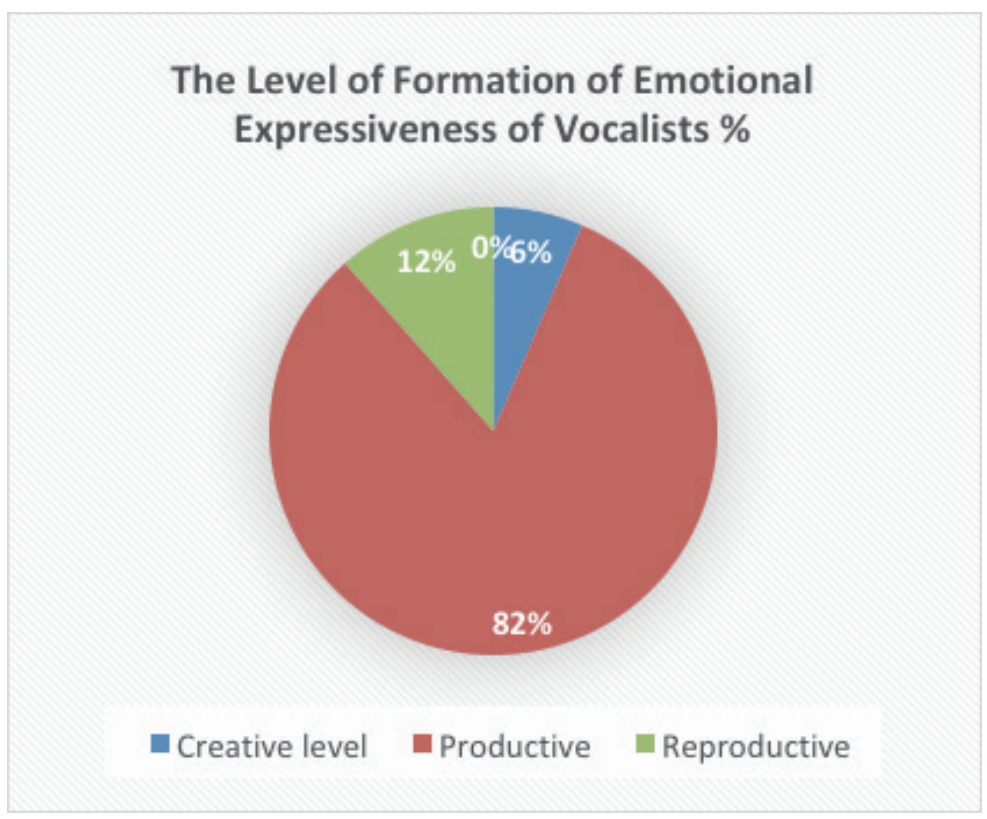

Figure 9. Levels of formation of emotional expressiveness of vocalists

The creative level of formation of emotional expressiveness was found in $6,5 \%$ of the total number of respondents (25 students).

The productive level of formation of emotional expressiveness of the future vocalist was diagnosed in $82 \%$ (321 people) of the total number of respondents.

The reproductive level of emotional expressiveness formation was recorded in $11,5 \%$ ( 45 people) of the total number of recipients.

\section{Conclusion}

Summarizing the results of the theoretical analysis of the problem, the results of a diagnostic cross-section of the levels of formation of emotional expressiveness of the future vocalist, we came to the following conclusions:

- The revealed contradictions regarding the problem of forming the emotional expressiveness of the future vocalist made it possible to understand the objective dialectic of the formation of this phenomenon by introducing axiological, interdisciplinary, and competence-based approaches to the training of students;

- Emotional expressiveness of a vocalist is an individual ability to model and transmit (broadcast) emotional states programmed in a vocal work, using the vocal capabilities of the performer, nonverbal signals, and means of musical expressiveness; 
- The structural components of the vocalist's emotional expressiveness are defined as follows: motivational and value, cognitive and analytical, emotional and empathic, practical and creative components;

- The level of formation of a student's emotional expressiveness is closely related to the peculiarities of his type of temperament;

- The results of the ascertaining experiment showed that $12 \%$ of students have a reproductive level of emotional expression formation, $82 \%$ of students have a productive level of emotional expression formation, and $6 \%$ have a creative level.

Summarizing the results of theoretical analysis of the problem, the results of the diagnostic section of the levels of emotional expression of the future vocalist, we came to the following conclusions: emotional expression of the vocalist, which we defined as the individual ability to model and transmit (translate) emotional states. Non-verbal signals and means of musical expression are essential components of the vocalist's professional training. The introduction of axiological, interdisciplinary, competence approaches in the training of students ensures the effectiveness of the formation of this phenomenon. We are determining the structural components of the vocalist's emotional expressiveness, and developing criteria and indicators based on them allowed us to diagnose the levels of its formation. The results of the observational experiment showed that $12 \%$ of students have a reproductive level of emotional expression, $82 \%$ of students have a productive level of emotional expression, and $6 \%$ - a creative level.

\section{Recommendation}

The future studies will focus on the selection of practical methods that will help teachers of vocal courses improve and accelerate the formation of emotional expressiveness of future vocalists in solo singing classes. The methodological model of emotional expressiveness formation is one of the priority tasks for us in further research of the outlined problem. The study results can be used to update the system of assessment of student achievement in the process of professional training of future vocalists. 


\section{Biodata of Authors}

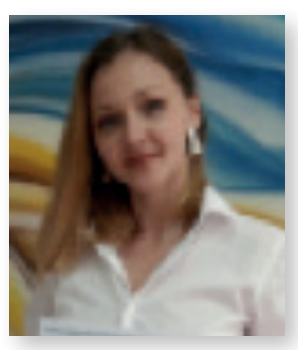

\section{Alina Shpyrka}

Interest of author: problems of professional training of future vocalists in institutions of higher art education, formation of emotional expression of students in solo singing classes, interdisciplinary connections in vocal training of students. Affiliation: Borys Grinchenko Kyiv University, Ukraine e-Mail: a.shpyrka@kubg.edu.ua ORCID: http://orcid.org/00000003-1415-0504

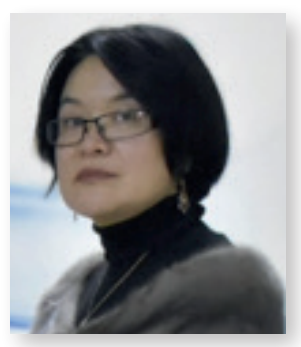

\section{Larysa Bondarenko, PhD}

Interest of author: problems of professional training of future teachers of music disciplines and teachers of music art, professional and spiritual self-development of students, communicative practices in continuing art education, introduction of axiological and hermeneutic approaches in instrumental and performance training of students of higher art education. Affiliation: Borys Grinchenko Kyiv University, Ukraine e-Mail: l.bondarenko@ kubg.edu.ua ORCID: https://orcid.org/0000-0001-6913-2448 Publons: https://publons.com/researcher/3242380/larysa-bondarenko/

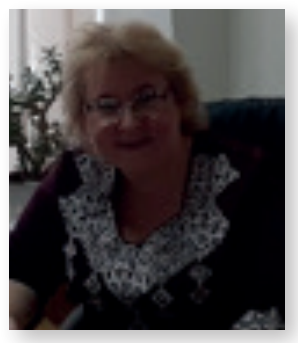

\section{Ganna Kondratenko, PhD}

Interest of author: creative development of future bachelors of music art and the formation of students' professional and personal values in the art educational environment. Professional training of music students based on axiology. Affiliation: Borys Grinchenko Kyiv University, Ukraine e-Mail: h.kondratenko@kubg.edu.ua ORCID: orcid.org/0000-0002-5035-4355

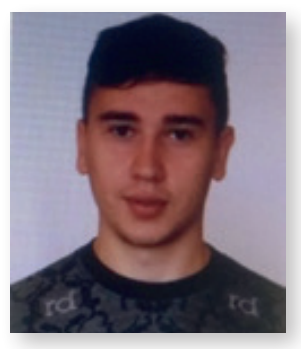

\section{Alexandr Shpyrka}

Interest of author: problems of professional training of future teachers of music art, formation of artistry of students in the process of professional training. Affiliation: Borys Grinchenko Kyiv University, Ukraine e-Mail: o.shpyrka@kubg.edu.ua ORCID: orcid.org/0000-0002-1855-1236 
References

A short dictionary of philosophy (1982).

I. V. Blauberg \& I. K. Pantin (eds.). Moscow: Politizdat.

Albor, M. (2016). On Music's Subtle Expressiveness. Avant: Trends in Interdisciplinary Studies, 7, 37-65.

Aranovskyi, M. (1998). Musical text. Structure and properties. Moscow.

Ayzenk, G. (1999). Personality structure. St. Petersburg: Yuventa.

Bonfeld, M. (1991). "Music. Language. Speech. Thinking" Experience in a systematic analysis of musical art, theses (1). Moscow.

Bukotzer, M. (1985). "Musikanalyse und Musikdeutung". Schweizerische Musikzeitung: 97 - 115.

Chebotarenko, O. (1997). "Culturological aspects of the performing form in music" dissertation of candidate of Art Studies: specialty 17.00.01 "Theory and History of Culture”. Odessa.

Condon, S. (2018). Preparing an emotionally expressive vocal performance. European Journal of Philosophy in Arts Education, 3 (1), 87120. Retrieved from http://www.ejpae. com/index.php/EJPAE/article/view/29

Cooke, D. (1959). The language of music. Oxford: Oxford University Press.

Dahlhaus, C. (1982). Systematiche Musikwissenschaft. Wiesbaden: Verlag.

Dictionary of the Ukrainian language in 11 volumes (1971). Kiev: Scientific Thought.

Eliseyev, O. P. (2003). Praktikum po psikhologii lichnosti [Workshop on personality psychology]. St. Petersburg.

Folomyeyeva H.A. (2012). Innovative heritage of modern vocal pedagogy in the teaching of special courses on stage at the Faculty of Arts]. Pedagogy and psychology. 617, 184-189.

Fomin, V. (1973). "The way music exists and the methodology of comparative analysis" Musical Art and Science, volume 2: 99 - 134. Moscow.

Friedman, H. S., Prince, L. M., Riggio, R. E., \& DiMatteo, M. R. (1980a). Understanding and assessing nonverbal expressiveness: The affective communication test. Journal of Personality and Social Psychology, 39, 333-351.

Friedman, H. S., Riggio, R. E., \& Segall, D. O. (1980). Personality and the enactment of emotion. Journal of Nonverbal Behavior, 5(1), 35-48. https:// doi.org/10.1007/BF00987053

Golovey, L. A., \& Rybalko, E. F. (2001). The study of the need to achieve: a workshop on age psychology. St. Petersburg.

Gross, J. J., \& John, O. P. (1997). Revealing feelings: Facets of emotional expressivity in self-reports, peer ratings, and behavior. Journal of Personality and Social Psychology, 72(2), 435-448. https: / / doi.org/10.1037/0022-3514.72.2.435

Grozan, S. (2015). The problem of 
competencies in music education Scientific notes [Kirovograd State Pedagogical University named after Vladimir Vynnychenko]. Ser.:Pedagogical sciences, 139, 144-146. Retrieved from http://nbuv. gov.ua/UJRN/Nz_p_2015_139_39.

Hryn, L. O. (2014). Diagnosis of the formation of vocal skills of the future actor of musical and dramatic theater. In: Scientific publication. Guidelines. Zaporizhzhia: ZNU.

Humrichouse, J. J. (2010). The hierarchical structure of emotional expressivity: scale development and nomological implications. Ph.D. thesis, University of lowa. Retrieved from http://ir.uiowa.edu/etd/519.

Hyunsin, P., \& Chang, D. Y. (2010). Statistical model based emotional singing voice synthesis by FO contour modification. Department of Electrical Engineering, Korea Advanced Institute of Science and Technology (KAIST).

Juslin, P. N. (2013). What does music express? Basic emotions and beyond. In: Frontiers in Psychology, 4, Article 596.

Korykhalova, Nataliya. (1979). "Interpretation of music" Theoretical problems of musical performance and a critical analysis of their development in modern bourgeois aesthetics. Leningrad: Muzyka.

Kotlyar, G. M., \& Morozov, V. P. (1976). On acoustic correlates of emotional expressiveness of vocal speech. Moscow.

Kucheruk, O. S. (2012). Characteristics of the motivational-value component of inclusive competence of the future teacher. Scientific journal of NPU named after MP Drahomanov. Series 16: Creative personality of the teacher: problems of theory and practice, 18, 20 23. Retrieved from http://nbuv.gov.ua/ UJRN/Nchnpu_016_2012_18_7

Laukka, P. (2017). Vocal Communication of Emotion. In: V. Zeigler-Hill \& T. Shackelford (eds) Encyclopedia of Personality and Individual Differences. Springer, Cham. Retrieved from https: // doi.org/10.1007/978-3-319-280998_562-1

Losev, Aleksey. (1995). "Music as a subject of logic. The form. Style. Expression": 405 - 602. Moscow.

Malinkovskaya, A. (1990). "Piano performing intonation" Problems of artistic intonation on the piano and analysis of its development in the methodological and theoretical literature of the XVI - XX centuries: [essays]. Moscow.

Medushevskyi, V. (1989). "Musical thinking and the logos of life" Musical thinking: essence, categories, and aspects of research: $18-27$. Kiev.

Nikandrov, V. V. (2009). Psychology: a textbook. Moscow: Volters Kluver.

Oleksiuk, O. M. (2017). Development of spiritual potential of personality in post-non-classical art education: [monograph]. Kyiv. Univ. B. Hrinchenko.

Oleksiuk, O., Bondarenko, L., Cherkasov, V., Kosinska, N., \& Maievska, A. (2019). Innovative Model of Communicative 
Practices. Journal of History Culture and Art Research, 8(2), 244-252. doi:http:// dx.doi.org/10.7596/taksad.v8i2.2109

Poluboiaryna, I. I. (2012). The role of temperament in the formation of individual style of gifted students of music specialties. In: Problems of modern pedagogical education: coll. Science. wash. Series: Pedagogy and psychology. Yalta: RVV KHU, 237-244. [in Ukrainian]

Psychological Dictionary (1982). V. I. Woitk (ed.). Kyiv: High School.

Riggio, H. R., \& Riggio, R. E. (2002). Emotional expressiveness, extraversion, and neuroticism: A meta-analysis. Journal of Nonverbal Behavior, 26(4), 195-218. Retrieved from https://doi. org/10.1023/A:1022117500440

Rogov, E. I. (1999). Desktop book by a practical psychologist. Book 2. Moscow.

Rokeach, M. (1973). The nature of human values. New York: Free Press.

Romanenko, V. O. (2012). Problems of analysis of emotions in singing in the context of arts XXI. In: Society: philosophy. history. culture. Publishing house "Khors".

Samoilenko, A. (2002). "Musicology and methodology of humanitarian knowledge" The problem of dialogue: [monograph]. Odessa.

Shemyakin, O. (2011). "A musical work as a way of knowing reality" [Extended abstract of candidate's thesis: major 09.00.13 "Philosophy and history of religion, philosophical anthropology, philosophy of culture"]. Moscow.
Shpak, M. (2009). Emotional culture of a teacher as a factor in the humanization of pedagogical education. Proceedings. Series: Pedagogy, 5, 49-52.

Tkach, M. M., \& Oleksiuk, O. M. (2021). Value-based orientations as a normativeregulatory mechanism for the formation of professional worldview of future music teachers. Linguistics and Culture Review, 5(S2), 522-536. https:// doi.org/10.37028/lingcure.v5nS2.1388.

Trierweiler, L. I., Eid, M., \& Lischetzke, T. (2002). The structure of emotional expressivity: Each emotion counts. Journal of Personality and Social Psychology, 82(6), 1023-1040. Retrieved from https://doi.org/10.1037/00223514.82.6.1023

Tszinkhen, H. (2015). Formation of stage culture of future teachers of musical art by means of pop singing: dissertation abstract. Kyiv: National Pedanonic University named after M. P. Drakhmanov.

Yeroshenko, O. V. (2008). Emotional sphere in vocal creativity: musicalaesthetic and performance aspects. Dissertation in art history. Kharkiv: Kharkiv State University I. P. Kotlyarevskoho.

Zelinska, T. M., \& Mykhailova I. V. (2009). Workshop on General Psychology: Textbook manual. Kiev: Karavela. 